\title{
Diffuse sky radiation influences the relationship between canopy PRI and shadow fraction
}

\section{Mõttus, Matti}

2015

Mõttus , M , Takala , T L H, Stenberg , P , Knyazikhin , Y , Yang , B \& Nilson , T 2015 , '

Diffuse sky radiation influences the relationship between canopy PRI and shadow fraction ' ,

ISPRS Journal of Photogrammetry and Remote Sensing , vol. 105 , pp. 54-60 . https://doi.org/10.1016/j.isprsjprs.20

http://hdl.handle.net/10138/155705

https://doi.org/10.1016/j.isprsjprs.2015.03.012

acceptedVersion

Downloaded from Helda, University of Helsinki institutional repository.

This is an electronic reprint of the original article.

This reprint may differ from the original in pagination and typographic detail.

Please cite the original version. 


\title{
Diffuse sky radiation influences the relationship between canopy PRI and shadow fraction
}

\author{
Matti Mõttus ${ }^{\mathrm{a}, *}$, Tuure L. H. Takala ${ }^{\mathrm{a}}$, Pauline Stenberg ${ }^{\mathrm{b}}$, Yuri Knyazikhin ${ }^{\mathrm{c}}$, Bin Yang ${ }^{\mathrm{d}, \mathrm{c}}$, Tiit Nilson ${ }^{\mathrm{e}}$ \\ ${ }^{a}$ Department of Geosciences and Geography, University of Helsinki, P.O. Box 68, FI-00014 Finland \\ ${ }^{b}$ Department of Forest Sciences, University of Helsinki, P.O. Box 27, FI-00014 Finland \\ ${ }^{c}$ Department of Earth and Environment, Boston University, Boston, Massachusetts 02215, USA \\ ${ }^{d}$ Institute of RS and GIS, School of Earth and Space Sciences, Peking University, Beijing 100871, China \\ ${ }^{e}$ Tartu Observatory, Tõravere, Nõo vald, 61602 Tartumaa, Estonia
}

\begin{abstract}
The Photochemical Reflectance Index (PRI) of green leaves is an indicator of photosynthetic downregulation: when the photosynthetic apparatus is close to the saturation limit, PRI becomes dependent on light conditions. Therefore, by measuring the PRI of leaves under different local irradiance conditions, it should be possible to determine the saturation level of the leaves and obtain information on the light use efficiency (LUE) of a vegetation canopy. The dependence of PRI on the ratio of sunlit to shaded foliage (quantified by the canopy shadow fraction) in the field of view of an instrument has been used to remotely measure canopy LUE on clear days. However, besides photosynthetic downregulation, the dependence of canopy PRI on shadow fraction is affected by the blue sky radiation caused by scattering in the atmosphere. To quantify this effect on remotely sensed PRI, we present the underlying definitions relating leaf and canopy PRI and perform the required calculations for typical midsummer conditions in Central Finland. We demonstrate that the effect of blue sky radiation on the variation of PRI with canopy shadow fraction is similar in shape and magnitude to that of LUE variations reported in literature.
\end{abstract}

Keywords: Vegetation; Hyper spectral; Atmosphere; Modelling; Geometric; Multiangular; Light use efficiency; Shadow fraction

\section{Introduction}

Under natural irradiation conditions, the spectral properties of leaves are dominated by diffuse scattering of incident light by leaf inner structures (Grant, 1987). Within-leaf concentrations of biological pigments (e.g., chlorophyll or carotenoids) thus strongly influence leaf spectral scattering by absorbing radiation with specific wavelengths. The spectrally selective absorption can be used to determine pigment concentrations rapidly and nondestructively using optical measurements.

Gamon et al. (1992) demonstrated that leaf optical properties at $531 \mathrm{~nm}$ track the epoxidation state of xanthophyll cycle pigments. The three pigments (zeaxanthin, antheraxanthin and violaxanthin) involved in the cycle have different absorption coefficients at this particular wavelength in the green part of the optical spectrum. The xanthophyll pigment interconversion cycle is activated by excess light and it has an important role in leaf photoprotection. Under saturating irradiance

\footnotetext{
${ }^{2}$ Publoshed in ISPRS Journal of Photogrammetry and Remote Sensing 105 (2015), 54-60, doi:j.isprsjprs.2015.03.012 (C)Elsevier

*Corresponding author

Email address: matti.mottus ahelsinki.fi (Matti Mõttus)
}

conditions, violaxanthin is converted to zeaxanthin creating a pathway for dissipating excess light energy as heat (Demmig-Adams and Adams, 2006). Therefore, optical measurements can be used to track the photosynthetic downregulation of a leaf, and offer a fast and non-destructive way to measure its photosynthetic status, potentially from a large distance.

The influence of the xanthophyll cycle on the optical properties of the leaves is commonly quantified using the Photochemical Reflectance Index (Gamon et al., 1992) defined as

$$
\mathrm{PRI}=\frac{\omega(531)-\omega(570)}{\omega(531)+\omega(570)},
$$

where $\omega(\lambda)$ is the spectral albedo of a canopy element (leaf, needle) at the wavelength $\lambda$ (in nanometers), i.e., the fraction of radiation reflected or transmitted by the element (Knyazikhin et al., 2011, 2013). Optical properties at $570 \mathrm{~nm}$ are used for reference in Eq. (1): at this wavelength, $\omega(\lambda)$ is not affected by pigment interconversions.

The PRI defined by Eq. (1) for an individual leaf is directly related to its photosynthetic efficiency $\varepsilon$ defined as the ratio of photochemically harvested $\mathrm{CO}_{2}$ to absorbed photosynthetically active radiation. Unfortunately, the leaf-level relationships are masked by other 
biophysical variables in the reflectance signal of a vegetation canopy. Stand-level light use efficiency (LUE) cannot be inferred from traditional, mono-angle remote PRI observations (Hilker et al., 2013). However, the variation in leaf PRI with canopy location (sun or shade) makes it possible to infer canopy LUE from the derivative of PRI with respect to the shadow fraction $\alpha_{S}$ (Hilker et al., 2010, 2011a). Under normal mid-day clear-sky irradiance conditions, sun-exposed leaves experience saturating light conditions. Their PRI values become different from those of shaded leaves making canopy PRI a function of the fraction of shadowed foliage in the instantaneous field-of-view (IFOV) of the spectroradiometer. This was demonstrated both theoretically and empirically by Hall et al. (2011) using multiangular optical measurements from a flux tower and a remote sensing satellite.

All the theoretical calculations cited above are based on a direct comparison of PRI measurements made on clear days under different view angles ignoring scattering in the atmosphere and multiple scattering in the vegetation canopy. Indeed, it is rather trivial that in case photons undergo a single scattering event between the source (sun) and the sensor, a normalized difference reflectance index (such as PRI) does not change with the viewing geometry unless the reflectance value in one of its bands changes. In the visible part of the spectrum including the wavelengths used in PRI, multiple scattering inside the vegetation canopy can be ignored to a reasonable accuracy. However, this may not be the case for the spectrally selective scattering in the atmosphere before the photons enter the canopy, especially under clear skies. Thus far, the effects of the atmosphere on measured canopy PRI have been investigated only to a limited extent. Hall et al. (2011) demonstrated that the influence of atmospheric scattering and absorption on PRI can be ignored for canopy-reflected radiation. The extent to which scattering in the cloudless atmosphere - or blue sky radiation - affects the PRI $-\alpha_{S}$ relationship has not been investigated yet.

The aim of our investigation is to present an analysis and model-based calculations of the non-biochemical factors affecting retrieval of canopy LUE from multiangular measurements of PRI. In other words, to untangle the geometric and biophysical causes of the variation of PRI with view angle, we keep leaf optical properties constant with the shadow fraction. We start by specifying the physical basis for relating multiangular canopy and leaf reflectance measurements. Using data from literature, we perform a quantitative analysis of the purely geometric effects interfering with remote measurement of the leaf-level $\varepsilon$.

\section{Theory and materials}

\subsection{Leaf and canopy reflectance}

The reflectance factor of a forest when measured directly above its canopy is defined as the ratio of the actual radiance scattered into the IFOV of the spectroradiometer $\left(I_{F}\right)$ to the theoretical value obtained when measuring a non-absorbing Lambertian (i.e., diffusely reflecting) surface under identical irradiation conditions $\left(I_{L}\right)$

$$
R(\lambda)=I_{F}(\lambda) / I_{L}(\lambda)
$$

Thus, for a direct retrieval of $R(\lambda)$, two radiation measurements have to be made. In remote sensing applications, an air-, satellite- or mast-born instrument is used to measure the radiance reflected by the object. The additional measurement of the radiance produced by the totally reflecting Lambertian surface can be taken (near-)simultaneously with the reflectance measurement (e.g., Hilker et al., 2010). Alternatively, it can be replaced by a numerical computation using the relatively stable solar irradiance spectrum and an atmospheric radiative transfer model. Further, instead of $I_{L}(\lambda), R(\lambda)$ may be expressed using the flux density of the radiative energy incident on the top-of-canopy surface, or the incident spectral irradiance $F(\lambda)$. As the bidirectional reflectance distribution factor of a nonabsorbing Lambertian surface, $R_{L} \equiv \pi^{-1}$, and $I_{L}(\lambda) \equiv$ $R_{L} F(\lambda)$, we obtain

$$
R(\lambda)=\pi I_{F}(\lambda) / F(\lambda) .
$$

In more technical terms, the reflectance factor defined by Eq. (2) is the hemispherical-directional, or, for a sensor with a wide IFOV, hemispherical-conical reflectance factor (Schaepman-Strub et al., 2006). It is a weighted average of the theoretical reflectance factors obtained under diffuse-sky and direct solar irradiation conditions.

Similarly to Eq. (2), we obtain from the defining equation for the spectral albedo $\omega(\lambda)$ of a canopy element (leaf, shoot, needle, etc. depending the actual canopy structure)

$$
\omega(\lambda)=\pi \bar{I}_{F}(\lambda) / \phi(\lambda),
$$

where $\bar{I}_{F}(\lambda)$ is the spectral radiance originating from the element averaged over all directions and all element area, and $\phi(\lambda)$ is the average spectral irradiance incident on the total (all-sided) surface area of the element. In case of a completely closed canopy, we may ignore the contribution of understory and assume that the radiance $I_{F}$ is contributed by canopy elements only. Further, if we have a remote sensing instrument with sufficiently high angular (or spatial) resolution, we may (at least theoretically) identify the individual canopy element producing the canopy reflectance signal. In 
this case, when we measure the canopy-leaving radiance $I_{F}(\lambda)$, we record the radiance scattered by an individual leaf. Next, we will make a common assumption in vegetation remote sensing: we will ignore the angular variation in leaf-scattered $I_{F}$ and take $I_{F}=\bar{I}_{F}$ (e.g., assume the leaves in a broadleaf canopy to be biLambertian with equal reflectance and transmittance). Now, we may solve Eqs. (3) and (4) for the common variable $I_{F}(\lambda)$ to arrive at

$$
R(\lambda)=\omega(\lambda) \frac{\phi(\lambda)}{F(\lambda)} .
$$

Eq. (5) explicitly connects the canopy reflectance factor $R(\lambda)$ with the optical properties of a single canopy element, $\omega(\lambda)$. Thus, it can be used to scale reflectance between the structural levels of the basic scattering element and of the whole canopy.

No actual remote sensing instrument can distinguish individual leaves. However, it is possible to choose observation directions such that the IFOV of the instrument is dominated by canopy elements with specific irradiation conditions. For example, elements observed in the backscattering (hotspot) direction are all sunlit; in the darkspot (coldspot) direction, shaded elements dominate. Therefore, in practical remote sensing applications, the $\phi(\lambda)$ in Eqs. (4) and (5) quantifies the average irradiance incident on all sides of visible canopy elements under a specific measurement geometry.

For the canopy-level PRI we can now write using Eq. (5)

$$
\begin{aligned}
\operatorname{PRI}_{C} & =\frac{R(531)-R(570)}{R(531)+R(570)} \\
& =\frac{\omega(531) \frac{\phi(531)}{F(531)}-\omega(570) \frac{\phi(570)}{F(570)}}{\omega(531) \frac{\phi(531)}{F(531)}+\omega(570) \frac{\phi(570)}{F(570)}} .
\end{aligned}
$$

We can further define the spectral distortion factor $\eta_{P R I}$ as the irradiance ratio

$$
\eta_{P R I}=\frac{\phi(531) F(570)}{\phi(570) F(531)}
$$

and multiply both the numerator and denominator of the fraction on the right hand side Eq. (6) by $F(570) / \phi(570)$ to obtain a more compact result,

$$
\mathrm{PRI}_{C}=\frac{\omega(531) \eta_{P R I}-\omega(570)}{\omega(531) \eta_{P R I}+\omega(570)}
$$

Based on Eq. (8), $\mathrm{PRI}_{C}$ is a nonlinear function of not only leaf optical properties, but also the average irradiation conditions of visible canopy elements quantified by $\eta_{P R I}$. Even if the optical properties of the elements remained constant, $\mathrm{PRI}_{C}$ would be a function of the spectral composition of the radiation incident on

\begin{tabular}{|c|c|c|}
\hline Parameter & Unit & Value \\
\hline $\mathrm{H}_{2} \mathrm{O}$ & $\mathrm{g} \mathrm{cm}^{-2}$ & 1.8 \\
\hline Ozone & Dobson unit & 340 \\
\hline $\mathrm{AOT}$ at $550 \mathrm{~nm}$ & & 0.18 \\
\hline \multicolumn{3}{|c|}{ Fractions of aerosol types } \\
\hline dust-like & $\%$ & 29 \\
\hline water-soluble & $\%$ & 66 \\
\hline oceanic & $\%$ & 2 \\
\hline soot & $\%$ & 3 \\
\hline Solar zenith angle & degree & 50 \\
\hline
\end{tabular}
the leaves, needles or shoots visible to the sensor and therefore depend on the sun-sensor geometry.
Table 1: The input parameters of the $6 \mathrm{~S}$ atmospheric radiative transfer model.

\subsection{Spectral irradiance at the top of the canopy}

The spectral irradiance $F(\lambda)$ incident on the horizontal surface at the top of a vegetation canopy varies greatly with time and space. The total amount of energy reaching the surface of the planet at a particular location is mostly determined by the orientation of the location with respect to the sun (i.e., solar elevation), the thickness and composition of the atmosphere, and the presence of clouds.

In the example computations we have used data from Hyytiälä, Finland, in the European southern boreal forest zone. We retrieved the GOCART (Goddard Chemistry Aerosol Radiation and Transport, Chin et al., 2002) atmospheric composition for Central Finland using the Giovanni Web-based tool ${ }^{1}$ (Acker and Leptoukh, 2007) for the peak growing season (June to August) of $2000-2006$. As remote sensing observations as well as most other spectral measurements are made under clear skies, the contribution of clouds was ignored. The top-of-canopy spectral irradiance was simulated with the $6 \mathrm{~S}$ atmospheric radiative transfer code (Vermote et al., 1997). The input parameters for $6 \mathrm{~S}$ are given in Table 1.

\subsection{Spectral irradiance incident on a canopy element}

The spectral irradiance intercepted by visible canopy elements in a vegetation canopy on a clear day can be divided into three components:

1. The direct solar irradiance $\phi_{0}(\lambda)$,

2. The diffuse sky irradiance $\phi_{\text {dif }}(\lambda)$, and

3. Canopy- and soil-scattered irradiance.

First, let us calculate the average direct solar irradiance $\phi_{\odot}$ incident on a convex canopy element at the top of canopy,

$$
\phi_{\odot}(\lambda)=\frac{F_{d i r}(\lambda) P\left(\vartheta_{0}\right)}{\cos \vartheta_{0}},
$$

where $F_{d i r}$ is the direct solar irradiance on the horizontal top-of-canopy surface, $P(\vartheta)$ is the ratio of average projected area of the element in the direction

\footnotetext{
${ }^{1}$ http://disc.sci.gsfc.nasa.gov/giovanni
} 


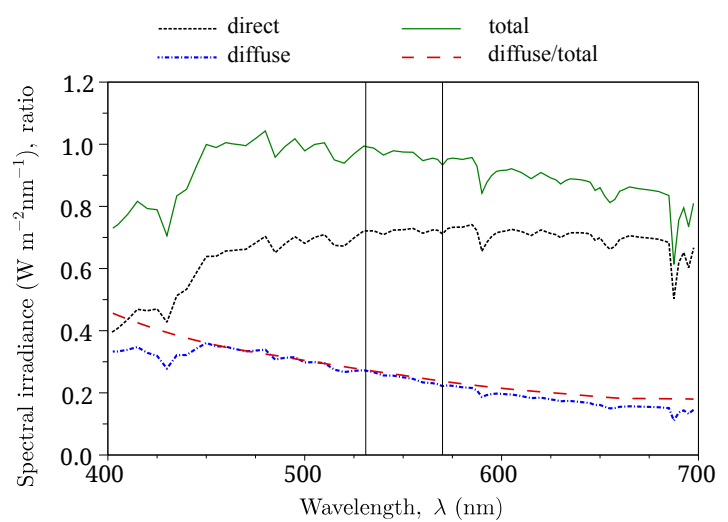

Figure 1: The solar spectrum and the ratio of diffuse to total downward spectral irradiance below the atmosphere calculated with the $6 \mathrm{~S}$ model. Input parameters are given in Table 1. The two wavelength used in calculating PRI (531 and $570 \mathrm{~nm}$ ) are marked with vertical lines.

given with the polar angle $\vartheta$ to its total surface area, and $\vartheta_{0}$ is the solar zenith angle. Now, we can define the shadow fraction $\alpha_{S}$ using the ratio of the average direct solar irradiance $\phi_{0}$ on visible canopy elements to that on a single element at the top of canopy, $1-\alpha_{S}=\phi_{0}(\lambda) / \phi_{\odot}(\lambda)$. Thus, the average direct solar irradiance intercepted by all sides of visible canopy elements (i.e., the first component in the list above) equals

$$
\phi_{0}(\lambda)=\left(1-\alpha_{S}\right) \phi_{\odot}(\lambda) .
$$

The second component in the list in the beginning of this section, the average diffuse sky irradiation on visible canopy elements, $\phi_{\text {dif }}(\lambda)$, depends on the diffuse flux density at the top of the canopy, $F_{d i f}(\lambda)$ (a function of solar elevation and atmospheric conditions), and the average fraction $\alpha_{U}$ of unobstructed sky for the visible canopy elements. Naturally, the full sky dome is visible only to the very topmost elements and the fraction of blocked sky averaged over visible canopy elements depends on both canopy structure and view angle. Further, as $\phi_{d i f}$ is the average of the blue sky irradiance on all surface area while only half of the surface of any convex object is (on the average) facing upwards, $\phi_{d i f}(\lambda)=\frac{1}{2} \alpha_{U} F_{d i f}(\lambda)$. Finally, we calculate the average spectral irradiance contributed by radiation incident on the canopy, $\phi_{I}(\lambda)=\phi_{d i f}(\lambda)+\phi_{0}(\lambda)$, as

$$
\phi_{I}(\lambda)=\frac{1}{2} \alpha_{U} F_{d i f}(\lambda)+\left(1-\alpha_{S}\right) \frac{F_{d i r}(\lambda) P\left(\vartheta_{0}\right)}{\cos \vartheta_{0}} .
$$

For flat leaves, $P(\vartheta)$ is commonly expressed using the the Ross-Nilson G-function (projection of unit onesided leaf area in the direction given by the polar angle $\vartheta), P(\vartheta)=\frac{1}{2} G(\vartheta)$. After inserting this expression into Eq. (11), we obtain for a leaf canopy

$$
\begin{aligned}
& \phi_{I, \text { leaf }}(\lambda) \\
& =\frac{1}{2}\left[\alpha_{U} F_{d i f}(\lambda)+\left(1-\alpha_{S}\right) \frac{F_{d i r}(\lambda) G(\vartheta)}{\cos \vartheta_{0}}\right] .
\end{aligned}
$$

For shoots, equations equivalent to Eqs. (9) and (11) can be derived using the shoot silhouette to total area ratio, $\operatorname{STAR}(\vartheta)$, and its spherically averaged counterpart, STAR. Additionally, because shoots are not convex objects, we need first to define their outer surface, or the convex shell of a shoot. In the context of this analysis, the exact shape of the shell is not relevant. It suffices that the convex shoot shell has a silhouette area identical to that of the shoot in all directions. The average direct solar irradiance incident on the surface area of the convex shoot shells of visible shoots can be shown to equal

$$
\begin{aligned}
& \phi_{0, \text { shoot }}(\lambda) \\
&=\left(1-\alpha_{S}\right) \frac{1}{4} \frac{F_{d i r}(\lambda)}{\cos \vartheta_{0}} \frac{\operatorname{STAR}\left(\vartheta_{0}\right)}{\overline{\operatorname{STAR}}} .
\end{aligned}
$$

The average spectral irradiance on the convex shells of visible shoots contributed by radiation incident on the canopy thus becomes

$$
\begin{aligned}
& \phi_{I, \text { shoot }}(\lambda) \\
& =\frac{1}{2} \alpha_{U} F_{\text {dif }}(\lambda)+\frac{1}{4}\left(1-\alpha_{S}\right) \frac{F_{d i r}(\lambda)}{\cos \vartheta_{0}} \frac{\operatorname{STAR}\left(\vartheta_{0}\right)}{\overline{\operatorname{STAR}}} .
\end{aligned}
$$

In later computations, we will assume $P(\vartheta) \equiv \frac{1}{4}$, i.e., that the elements have no preferred direction (Lang, 1991). For the fraction of unobstructed sky for visible canopy elements, we will use the intuitive value $\alpha_{U}=\frac{1}{2}$ which can be analytically shown to equal the view-angle-averaged $\alpha_{U}$ in a closed random horizontal leaf canopy (i.e., a canopy where the flat horizontal scattering elements are distributed uniformly in space, Eq. (12) by Mõttus, 2007). For spherically symmetric shoots, $\left(\operatorname{STAR}\left(\vartheta_{0}\right)=\overline{\mathrm{STAR}}\right)$, the expression for $\phi_{0, \text { shoot }}(\lambda)$ (Eq. 13) becomes identical to that for leaves, $\phi_{0, \text { leaf }}(\lambda)$, with no preferred orientation $(G \equiv 0.5)$. This result is in agreement with the general Eq. (11) with $P(\vartheta) \equiv \frac{1}{4}$ and makes it unnecessary to distinguish between needleleaf and flatleaf canopies in further analysis.

The third irradiance component in the list in the beginning of this section, canopy- and soil-scattered irradiance, has been ignored in previous analyses of multiangular measurements (Hilker et al., 2010, 2011b,a, 2013; Hall et al., 2011). Indeed, the reflectance of a boreal forest at the two visible wavelengths used in PRI is very low. For example, at peak growing season, the reflectance factors of the forest stands at 531 and $570 \mathrm{~nm}$ at Hyytiälä rarely exceed 0.03 (data not shown). As a rough approximation, we may assume that the average contribution of second- and higherorder scattering to the canopy reflectance signal is of the same order, i.e., not more than $5 \%$. We ignored within-canopy multiple scattering (i.e., photons which interact the canopy more than once) in further analysis by assuming $\phi_{0}(\lambda) \equiv \phi_{I}(\lambda)$. 


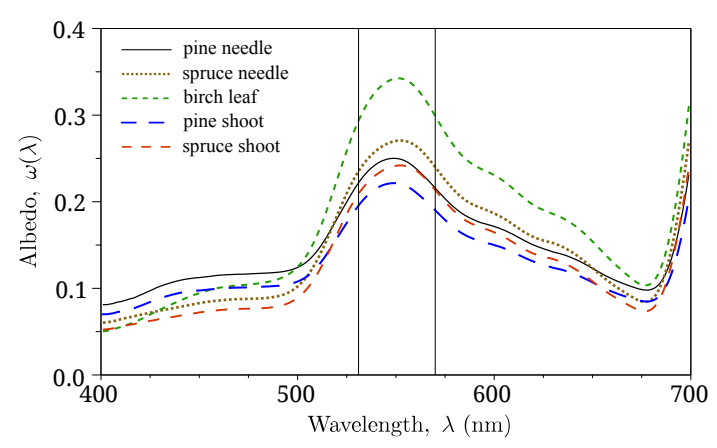

Figure 2: Spectra of the leaves, needles and shoots of boreal tree species. Vertical bars denote the two wavelengths used in PRI, 531 and $570 \mathrm{~nm}$.

The direct and diffuse irradiances on the horizontal top-of-canopy surface ( $F_{d i r}$ and $F_{d i f}$, respectively) were calculated using the $6 \mathrm{~S}$ atmospheric radiative transfer model as described above (Table 1, Fig. 1). Eqs. (9) and (11), when inserted into (7), quantify the relationship between the spectral distortion factor $\rho_{\text {PRI }}$ and the shadow fraction $\alpha_{S}$.

\subsection{Leaf and shoot albedo}

We used the leaf and needle reflectance data measured by Lukeš et al. (2013) in Hyytiälä in the summer of 2012 to simulate the canopy PRI (Eq. 6). Fully developed leaves and needles of the three main tree species (Scots pine, Norway spruce, and Silver birch) were picked from sunlit and shaded canopy locations. Spectral measurements were carried out in a laboratory using an integrating sphere. The measured directional-hemispherical reflectance and transmittance factors were added to obtain the leaf spectral albedo $\omega(\lambda)$. As we were interested only in the structural effects on PRI, we ignored the dependence of $\omega(\lambda)$ on irradiation conditions and averaged sunlit and shaded leaf spectra for each species. For spruce, we also averaged $\omega(\lambda)$ of current-year and older needles which were measured separately.

It is generally accepted that in needle-leaf canopies, the shoot should be used as the basic scattering unit (Oker-Blom and Kellomäki, 1983; Nilson and Ross, 1997). Therefore, we used the measured needle spectra of the coniferous species (spruce and pine) to calculate shoot albedo using the photon recollision probability theory (Rautiainen et al., 2012). The only parameter required for the scaling of needle to shoot, the photon recollision probability $p$, was calculated from the spherically averaged shoot silhouette to total area ra-

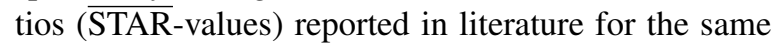
species and geographical area. For Scots pine, we used the STAR-value of 0.15 (Stenberg et al., 2001); for Norway spruce, we used 0.14 (Palmroth et al., 2002). Due to the low needle albedo in the visible wave-

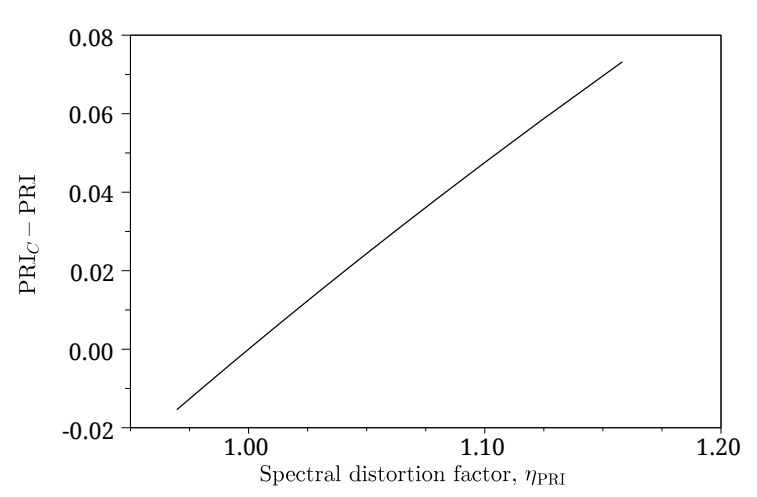

Figure 3: The difference between the PRI of a vegetation canopy and that of a leaf $\left(\mathrm{PRI}_{C}-\mathrm{PRI}\right)$ as a function of the spectral distortion factor $\eta_{P R I}$.

lengths, the clumping of needles into shoots has little effect on $\omega(\lambda)$ at 531 and $570 \mathrm{~nm}$ (Fig. 2).

\section{Results and discussion}

Under the average midsummer clear sky conditions, the ratio of diffuse irradiance to total downward flux $\left(F_{\text {dif }}(\lambda) / F(\lambda)\right)$ decreases with wavelength from close to $50 \%$ in violet to $20 \%$ in red. In green, it constitutes approximately $30 \%$ of the downwelling flux at the top of the forest canopy (Fig. 1). At the two wavelengths used in PRI, 531 and $570 \mathrm{~nm}, F_{\text {dif }} / F$ equals 0.275 and 0.237 , respectively. These canopy-level irradiation conditions induce variation in the spectral distribution of irradiation on the leaves (or conifer shoots) visible to a sensor, and thus the range of $\eta_{P R I}$ (Eq. 7). For completely shaded leaves, we obtained $\eta_{P R I}($ dif $)=$ 1.16 by setting $\phi_{I}(\lambda)=\frac{1}{4} F_{\text {dif }}(\lambda)$ in Eq. (7). At the other extreme are the leaves receiving only direct radiation, i.e., leaves located in canopy positions where gaps exist only in the direction of the sun and the observer. The irradiation conditions for such leaves were characterized by $\eta_{P R I}($ dir $)=0.95$, obtained by setting $\phi_{I}(\lambda)=\frac{1}{4} F_{d i r}(\lambda)$ in Eq. (7). For any view configuration, the irradiation conditions were in-between these two values given in Table 2 .

Although the leaf optical properties in Table 2 vary somewhat between species, the difference PRI $\mathrm{PR}_{C}-\mathrm{PRI}$ can, for all practical purposes, be treated as a function of the spectral distortion factor $\eta_{P R I}$ only (assuming leaf optical properties do not vary with $\alpha_{S}$ ). The range of $\eta_{P R I}$ in Table 2 translates into a $\mathrm{PRI}_{C}-\mathrm{PRI}$ range of -0.025 to 0.073 with positive $\eta_{P R I}$ values (shaded leaves) leading to $\mathrm{PRI}_{C}>\mathrm{PRI}$ (Fig. 3). The driving factor behind changes in the spectral distortion factor $\eta_{P R I}$ is the shadow fraction $\alpha_{S}$. The relationship between PRI ${ }_{C}-$ PRI and $\alpha_{S}$ obtained from Eqs. (7), (8) and (11) is strongly nonlinear (Fig. 4). As was the case with $\eta_{P R I}, \mathrm{PRI}_{C}-$ PRI depends only on the value of $\alpha_{S}$ 
Table 2: The optical properties of birch leaves, and pine and spruce shoots: $\omega(\lambda)$ is the spectral albedo; $\operatorname{PRI}_{C}($ dif $)$ and PRI $($ dir $)$ are the canopy PRI values when the field-of-view of the instrument is filled with foliage elements under completely diffuse $\left(\eta_{P R I}=1.16\right)$ and direct $\left(\eta_{P R I}=0.95\right)$ irradiation conditions, respectively.

\begin{tabular}{cccccc}
\hline species & $\omega(531)$ & $\omega(570)$ & leaf PRI & $\mathrm{PRI}_{C}($ dif $)$ & $\mathrm{PRI}_{C}(\mathrm{dir})$ \\
\hline \hline pine & 0.196 & 0.190 & 0.014 & 0.087 & -0.011 \\
spruce & 0.209 & 0.214 & -0.011 & 0.062 & -0.036 \\
birch & 0.294 & 0.299 & -0.009 & 0.064 & -0.034 \\
\hline
\end{tabular}

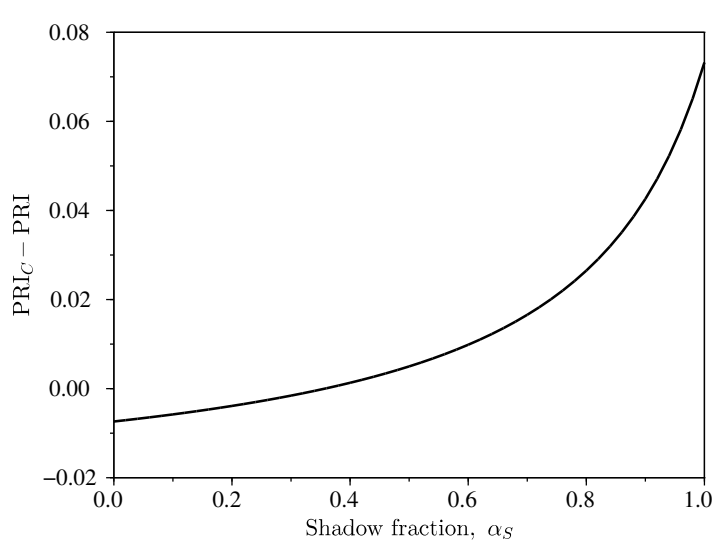

Figure 4: Dependence of the difference $\mathrm{PRI}_{C}-\mathrm{PRI}$ on the shadow fraction $\alpha_{S}$. Atmospheric conditions are described in Table 1.

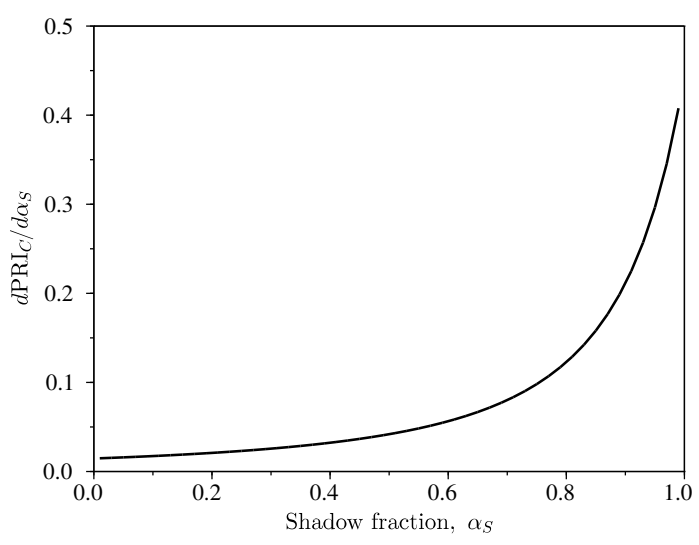

Figure 5: The dependence of the derivative of canopy PRI $\left(d \mathrm{PRI}_{C} / d \alpha_{S}\right)$ on the fraction of shadow included in the field of view of the measurement device calculated from the data in Fig. 4.

and the atmospheric conditions, but not on the $\omega(\lambda)$ values at 531 and $570 \mathrm{~nm}$.

According to Hall et al. (2011), changes in canopylevel PRI with $\alpha_{S}$ can be used to track the photosynthetic light use efficiency of a vegetation canopy in case multiple scattering can be ignored. They demonstrated that the partial derivative $\partial \mathrm{PRI}_{C} / \partial \alpha_{S}$ (which is equivalent to the $d \mathrm{PRI}_{C} / d \alpha_{S}$ calculated here) is strongly correlated with a quantity describing the photosynthetic downregulation in sunlit leaves - relative light use efficiency -, and can be used to infer photosynthetic effi-

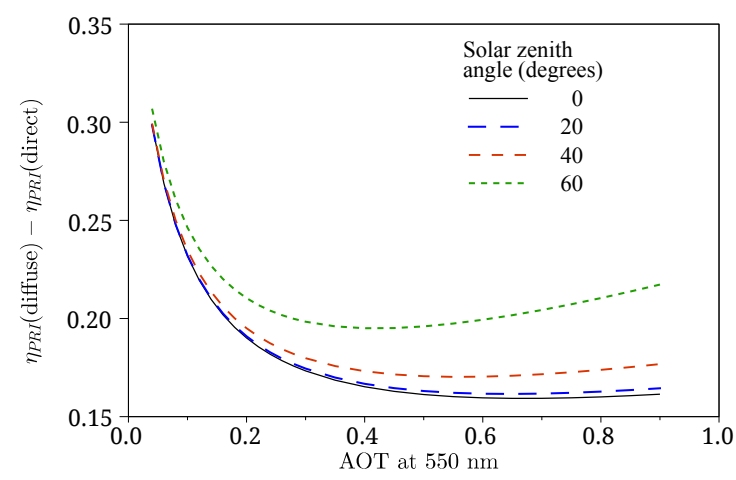

Figure 6: Dependence of the possible range of the spectral distortion factor, $\eta_{P R I}($ dif $)-\eta_{P R I}($ dir $)$, on the amount of atmospheric aerosol at different solar zenith angles as predicted by the $6 \mathrm{~S}$ radiative transfer model. Aerosol composition is given in Table 1.

ciency at the landscape level. However, in the presence of blue sky radiation (i.e., spectrally selective scattering in the atmosphere), the differences in the spectral irradiances on sunlit and shaded canopy elements cause variation in $d \mathrm{PRI}_{C} / d \alpha_{S}$ unrelated to any plant physiological processes (Fig. 5). Judging from the sample data presented by Hall et al. (2011), the variation caused by blue sky radiation can be of the same magnitude as that caused by changes in leaf LUE. Additionally, the blue sky radiation has the largest effect on $d \mathrm{PRI}_{C} / d \alpha_{S}$ for large shadow fraction values where the effect of photosynthetic downregulation on $d \mathrm{PRI}_{C} / d \alpha_{S}$ is the largest (Fig. 2 in Hall et al., 2011), i.e., far from the hotspot and backward-scattering directions. Thus, theoretically, the blue sky signal in the directional PRI is similar to the physiological one.

The range of the spectral distortion factor $\eta_{P R I}$, calculated as $\eta_{P R I}($ dif $)-\eta_{P R I}($ dir $)$, fully determines the range of the difference between the observed canopy and leaf PRI $\left(\mathrm{PRI}_{C}-\mathrm{PRI}\right)$. As we ignored the multiple scattering within the canopy, $\eta_{P R I}($ dif $)-\eta_{P R I}($ dir $)$ depends only on the atmospheric conditions (namely, the amount and composition of atmospheric aerosol) and solar zenith angle (Fig. 6). The value of $\eta_{P R I}($ dif $)-$ $\eta_{P R I}($ dir) is close to 0.2 for a wide range of atmospheric conditions. Using the near-linear relationship in Fig. 2, $\eta_{P R I}($ dif $)-\eta_{P R I}($ dir $)=0.2$ translates into $\mathrm{PRI}_{C}-\mathrm{PRI} \simeq 0.1$. Based on Fig. 6, the largest differences between $\mathrm{PRI}_{C}$ and PRI are expected for very 
clear skies and low sun angles. The effect of solar angle on $\mathrm{PRI}_{C}-\mathrm{PRI}$ is small for zenith angles below $40^{\circ}$.

In addition to solar zenith angle and atmospheric aerosol level, PRI $_{C}-$ PRI depends on the fraction of visible sunlit foliage, $1-\alpha_{S}$. Besides external factors such as solar and observation directions, the latter depends on the structure of the vegetation canopy. While it is clear that observations at $\alpha_{S}=0$ are possible in the hotspot direction, sunlit leaves can hardly be completely hidden at any observation angle. As $\mathrm{PRI}_{C}-\mathrm{PRI}$ is most sensitive to shadow fraction at large $\alpha_{S}$ values $\left(\alpha_{S} \gtrsim 0.9\right)$ which are practically non-existing, the actual range of $\mathrm{PRI}_{C}-\mathrm{PRI}$ is considerably reduced from 0.1. A simple numerical result can be obtained using the theoretical formulas for first order scattering of direct and blue sky radiation given by the radiative transfer theory in vegetation canopies (Ross, 1981; Nilson, 1991). In the case of a thick vegetation layer and spherical leaf orientation, these formulas yield the widelyused Ross-thick kernel in the kernel-driven approximation of bidirectional reflectance (Wanner et al., 1995). We further corrected the theoretical formulas for the hotspot effect in the exact hotspot direction (where the correction is trivial) and integrated over the hemisphere to obtain canopy-scattered blue sky radiation. The PRI difference in the hotspot (no shadows) and darkspot (maximum shadows) was 0.02 when we used the spectral albedo values for pine (Table 2 ) and $F_{\text {dif }} / F$ ratios of 0.275 and 0.237 for 531 and $570 \mathrm{~nm}$, respectively. However, this does not make the role of blue sky radiation insignificant for LUE estimation. The PRI differences with view angle reported in scientific literature also hardly ever reach values close to 0.1 (Hilker et al., 2008; Lewis et al., 2005), with most measurements yielding a value below 0.05 (e.g., Hall et al., 2008; Hilker et al., 2010; Middleton et al., 2009; Cheng et al., 2012. Therefore, the blue sky effect on angular PRI measurements described here cannot be ignored when retrieving the LUE of a vegetation canopy from multiangular observations.

The analysis presented here concerns only the scale of the effect of blue sky scattering on the angular variation of canopy PRI. We performed our calculations ignoring multiple scattering inside the canopy and the distribution of leaf surfaces. The scattering phase function was considered isotropic, an assumption that holds only approximately for the wavelengths used in PRI. We further used an approximate value for the fraction of unobstructed sky for the visible foliage and assumed a closed canopy, i.e., LAI $\rightarrow \infty$. In a more strict and detailed formulation, the direct solar irradiance on visible leaves is a function of view and illumination directions as well as the distribution of leaf surface normals (Ross, 1981; Myneni et al., 1989). Additionally, many other phenomena may induce an angular dependence in the link between leaf and canopy PRI. For a canopy which is not completely closed (as is the case in the boreal forests in Hyytiälä), the fractions of canopy and soil (or understory) in the sensor IFOV depend on the view angle. The spectral properties of soil or understory are generally different from that of overstory. The directional distribution of scattered radiation depends on wavelength (e.g., Grant, 1987; Bousquet et al., 2005; Mõttus et al., 2012; Mõttus and Rautiainen, 2013), mainly due to the reflectance component contributed by leaf (or needle) surface. For some canopies, the scattering of visible light in forward directions can be dominated by the specular component. The spectral dependency of scattering anisotropy may introduce an additional component in the angular distribution of canopy PRI which is independent from its LUE. In order to create a truly robust method for retrieving landscape level LUE from multiangular remote measurements, all factors potentially affecting the directionality of canopy PRI must be meticulously considered.

\section{Conclusions}

When the radiation scattered by a vegetation canopy under ambient clear-sky conditions is measured from multiple view angles, varying fractions of foliage in the sensor's field-of-view are either shaded or sunlit during each measurement. Also the spectral distributions of the radiation incident on sunlit and shaded leaves differ. At least partly, the latter is caused by the different spectral compositions of the direct and diffuse sky radiation at the surface level. We have demonstrated that the different spectral compositions of the two natural irradiation components are sufficient to produce a measurable angular variation in canopy PRI. The variation of PRI with shadow fraction - and thus view angle - discussed here is independent from the physiological PRI variation caused by radiation-induced interconversion of the xantophyll cycle pigments of sunlit leaves.

\section{Acknowledgements}

We are grateful to Dr. Albert Porcar-Castell for valuable discussions, and the Academy of Finland and University of Helsinki for funding the research.

\section{References}

Acker, J.G., Leptoukh, G., 2007. Online analysis enhances use of NASA Earth science data. Eos Transactions AGU 88, 14-17.

Bousquet, L., Lachérade, S., Jacquemoud, S., Moya, I., 2005. Leaf BRDF measurements and model for specular and diffuse components differentiation. Remote Sensing of Environment 98, 201211

Cheng, Y.B., Middleton, E., Zhang, Q., Corp, L., Dandois, J., Kustas, W., 2012. The photochemical reflectance index from directional cornfield reflectances: Observations and simulations. Remote Sensing of Environment 124, 444-453.

Chin, M., Ginoux, P., Kinne, S., Torres, O., Holben, B., Duncan, B., Martin, R., Logan, J.A., Higurashi, A., Nakajima, T., 2002. Tropospheric aerosol optical thickness from the gocart model and comparisons with satellite and sun photometer measurements. Journal of the Atmospheric Sciences 59, 461-483. 
Demmig-Adams, B., Adams, W.I., 2006. Photoprotection in an ecological context: The remarkable complexity of thermal energy dissipation. New Phytologist 172, 11-21.

Gamon, J., Penuelas, J., Field, C., 1992. A narrow-waveband spectral index that tracks diurnal changes in photosynthetic efficiency. Remote Sensing of Environment 44, 35-44.

Grant, L., 1987. Diffuse and specular characteristics of leaf reflectance. Remote Sensing of Environment 22, 309-322.

Hall, F., Hilker, T., Coops, N., 2011. PHOTOSYNSAT, photosynthesis from space: Theoretical foundations of a satellite concept and validation from tower and spaceborne data. Remote Sensing of Environment 115, 1918-1925.

Hall, F.G., Hilker, T., Coops, N.C., Lyapustin, A., Huemmrich, K.F., Middleton, E., Margolis, H., Drolet, G., Black, T.A., 2008. Multiangle remote sensing of forest light use efficiency by observing PRI variation with canopy shadow fraction. Remote Sensing of Environment 112, 3201-3211.

Hilker, T., Coops, N.C., Hall, F.G., Black, T.A., Wulder, M.A., Nesic, Z., Krishnan, P., 2008. Separating physiologically and directionally induced changes in PRI using BRDF models. Remote Sensing of Environment 112, 2777-2788.

Hilker, T., Coops, N.C., Hall, F.G., Nichol, C.J., Lyapustin, A., Black, T.A., Wulder, M.A., Leuning, R., Barr, A., Hollinger, D.Y., Munger, B., Tucker, C.J., 2011a. Inferring terrestrial photosynthetic light use efficiency of temperate ecosystems from space. Journal of Geophysical Research: Biogeosciences 116, G03014.

Hilker, T., Gitelson, A.A., Coops, N.C., Hall, F.G., Black, T.A., 2011b. Tracking plant physiological properties from multiangular tower-based remote sensing. Oecologia 165, 865-876.

Hilker, T., Hall, F., Coops, N., Collatz, J., Black, T., Tucker, C., Sellers, P., Grant, N., 2013. Remote sensing of transpiration and heat fluxes using multi-angle observations. Remote Sensing of Environment 137, 31-42.

Hilker, T., Hall, F.G., Coops, N.C., Lyapustin, A., Wang, Y., Nesic, Z., Grant, N., Black, T.A., Wulder, M.A., Kljun, N., Hopkinson, C., Chasmer, L., 2010. Remote sensing of photosynthetic lightuse efficiency across two forested biomes: Spatial scaling. Remote Sensing of Environment 114, 2863-2874.

Knyazikhin, Y., Schull, M.A., Stenberg, P., Mõttus, M., Rautiainen, M., Yang, Y., Marshak, A.L., Latorre Carmona, P., Kaufmann, R.K., Lewis, P., Disney, M.I., Vanderbilt, V., Davis, A.B., Baret, F., Jacquemoud, S., Lyapustin, A., Myneni, R.B., 2013. Hyperspectral remote sensing of foliar nitrogen content. Proceedings of the National Academy of Sciences of the United States of America 110, E2438.

Knyazikhin, Y., Schull, M.a., Xu, L., Myneni, R.B., Samanta, A., 2011. Canopy spectral invariants. part 1: A new concept in remote sensing of vegetation. Journal of Quantitative Spectroscopy and Radiative Transfer 112, 727-735.

Lang, A., 1991. Application of some of Cauchy's theorems to estimation of surface areas of leaves, needles and branches of plants, and light transmittance. Agricultural and Forest Meteorology 55, 191-212.

Lewis, P., Disney, M., Quaife, T., Nichol, C., Rebelo, L., 2005. CTCD CHRIS-Proba activities, in: Lacoste, H. (Ed.), Proceedings of the 3rd ESA CHRIS/Proba workshop. 21-23 March ESRIN, Frascati, Italy (ESA SP-593), ESA. p. 4 pp.

Lukeš, P., Stenberg, P., Rautiainen, M., Mõttus, M., Vanhatalo, K.M., 2013. Optical properties of leaves and needles for boreal tree species in Europe. Remote Sensing Letters 4, 667-676.

Mõttus, M., 2007. Photon recollision probability in discrete crown canopies. Remote Sensing of Environment 110, 176-185.

Mõttus, M., Rautiainen, M., 2013. Scaling PRI between coniferous canopy structures. IEEE Journal of Selected Topics in Applied Earth Observations and Remote Sensing 6, 708-714.

Mõttus, M., Rautiainen, M., Schaepman, M.E., 2012. Shoot scattering phase function for Scots pine and its effect on canopy reflectance. Agricultural and Forest Meteorology 154-155, 67-74.

Middleton, E., Cheng, Y.B., Hilker, T., Black, T., Krishnan, P. Coops, N., Huemmrich, K., 2009. Linking foliage spectral responses to canopy-level ecosystem photosynthetic light-use efficiency at a Douglas-fir forest in Canada. Canadian Journal of
Remote Sensing 35, 166-188.

Myneni, R., Ross, J., Asrar, G., 1989. A review on the theory of photon transport in leaf canopies. Agricultural and Forest Meteorology 45, 1-153.

Nilson, T., 1991. Approximate analytical methods for calculating the reflection functions of leaf canopies in remote sensing applications, in: Myneni, R., Ross, J. (Eds.), Photon-Vegetation Interactions. Springer-Verlag, Berlin-Heidelberg, pp. 161-190.

Nilson, T., Ross, J., 1997. The use of remote sensing in the modeling of forest productivity, in: Gholz, H.L., Nakane, K., Shimoda, H. (Eds.), Modeling radiative transfer through forest canopies: implications for canopy photosynthesis and remote sensing. Kluwer Academic Publishers, Dordrecht. chapter 2, pp. 23-60.

Oker-Blom, P., Kellomäki, S., 1983. Effect of grouping of foliage on the within-stand and within-crown light regime: Comparison of random and grouping canopy models. Agricultural Meteorology 28, 143-155.

Palmroth, S., Stenberg, P., Smolander, S., Voipio, P., Smolander, H., 2002. Fertilization has little effect on light-interception efficiency of Picea abies shoots. Tree Physiology 22, 1185-1192.

Rautiainen, M., Mõttus, M., Yáñez Rausell, L., Homolová, L., Malenovský, Z., Schaepman, M.E., 2012. A note on upscaling coniferous needle spectra to shoot spectral albedo. Remote Sensing of Environment 117, 469-474.

Ross, J., 1981. The Radiation Regime and Architecture of Plant Stands. The Hague: Dr. W. Junk Publishers.

Schaepman-Strub, G., Schaepman, M.E., Painter, T.H., Dangel, S., Martonchik, J.V., 2006. Reflectance quantities in optical remote sensing-definitions and case studies. Remote Sensing of Environment 103, 27-42.

Stenberg, P., Palmroth, S., Bond, B.J., Sprugel, D.G., Smolander, H., 2001. Shoot structure and photosynthetic efficiency along the light gradient in a Scots pine canopy. Tree Physiology 21, 805814

Vermote, E.F., Tanre, D., Deuze, J.L., Herman, M., Morcrette, J.J., 1997. Second Simulation of the Satellite Signal in the Solar Spectrum, 6S: An overview. IEEE Transactions on Geoscience and Remote Sensing 35, 675-686.

Wanner, W., Li, X., Strahler, A.H., 1995. On the derivation of kernels for kernel-driven models of bidirectional reflectance. Journal of Geophysical Research - Atmospheres 100, 21077-21089. 